\title{
Increase of brick masonry durability for external walls of buildings and structures
}

\author{
Tetiana Kropyvnytska ${ }^{1, *}$, Roksolana Semeniv ${ }^{1}$, and Hanna Ivashchyshyn ${ }^{1}$ \\ ${ }^{1}$ Lviv Polytechnic National University, Department of Building Production, Karpinskyy str. 6, 79013, \\ Lviv, Ukraine
}

\begin{abstract}
The current article is focused at efflorescence formation and durability of brick masonry. The chemical and phase composition, microstructure of efflorescence on brick and masonry mortar on exterior walls of buildings are studied. Improved properties of brick masonry for external walls of buildings are achieved by the use of masonry mortar based on multi-component cement, which contains zeolite. It is shown that the use of multi-component cement with low clinker content in the mortar reduces the content of calcium hydroxide and $\mathrm{SO}_{3}$. It is determined that synergistic combination of mineral additives of different groups with substantial reduction of cement clinker in cements containing zeolite, improves durability of brick masonry without efflorescence formation. Physic-chemical modification of mortar by complex air-entraining admixture allows obtaining high-quality modified mortars with improved quality parameters. The surface modification of ceramic bricks by silicon and acrylic compounds provides protection and durability of brick masonry of buildings and structure walls.
\end{abstract}

\section{Introduction}

Buildings and structures are exposed to the environmental factors (rainfall, temperature changes) during the exploitation. This has a negative impact on the physical and technical properties of brick masonry for external walls of buildings and salts formation on the surface of the masonry. One of the reasons of brick masonry destruction is readily soluble salts of sulphuric salts in the alkaline and alkaline earth metals from ceramic brick. They can connect the water of crystallisation forming crystal hydrates. The porous structure of ceramic bricks causes the diffusion of alkalis from cement mortars, reinforcing a destructive effect on the masonry. However, the formation of salt efflorescence on the brick masonry surface is also connected with the salt solution penetration in the brick. The salt efflorescence appear on the masonry, when we use the mortar, based on the Portland cement with the high content of clinker and the addition of lime. Herewith, calcium hydroxide, which is a product of Portland cement hydration, washed on the surface of the material and during the interaction with $\mathrm{CO}_{2}$ of the air forms efflorescence $[1,2]$.

On the other hand, increased content of $\mathrm{Ca}(\mathrm{OH})_{2}$ in cement and lime mortar leads to the more intensive leaching of lime and subsequent carbonation on the masonry surface to form

* Corresponding author: tkropyvnytska@ukr.net 
insoluble calcium carbonate efflorescence. Also one of the reasons of efflorescence forming is the use of well soluble frost-resistance additives and accelerators of hardening. In the process of installation, a high capacity to water absorption of ceramic bricks in masonry seams leads to dehydration of mortar mixture with forming a highly porous layer of the mortar. Free water from the masonry mortar, penetrating in the brick, dissolves the salts followed by crystallization of salt efflorescence not only on the surface but also in the pores. It results in the appearance of cracks and destruction of the masonry integrity during exploitation [3].

One of the effective ways to improve the durability of masonry and prevent the formation of salt efflorescence is the application of mortars, based on the cements with a low content of Portland cement clinker [4-6]. Herewith, an active mineral additive of natural origin, zeolite tuffs, plays the main role in building mortars. A high activity of zeolite tuffs (a large group of minerals - water aluminosilicate sodium and calcium from subclass of frame silicates) on the binding of lime and gypsum in the hydrated phases indicates the possibility of efficient use of the natural zeolites in cements for building mortars. At the same time, the presence of channels in the minerals structure of the zeolite group and high porosity of zeolite tuffs allow active absorption of $\mathrm{SO}_{3}$. The building mortar modified with natural zeolites is characterized by good sorption properties due to their porous structure and can accumulate a sufficient amount of salt [7-10].

Currently special attention is paid to mortars, modified with air entraining admixtures of new generation that improves the technological properties of mortar mixtures and mortar performance properties. The use of air entraining admixtures in building mortar excludes the addition of lime in their composition that provides the increased frost resistance of masonry without forming of salt efflorescence. The right choice of mortar composition determines the durability of masonry in different conditions of buildings exploitation [10, 11]. It is widely used the method of surface impregnation by repel compounds, resulting the reduction of porosity and permeability of the material, improve the performance properties and increase the durability of brick masonry. The main types of impregnating products used for the treatment of porous building materials mostly have repellent action that does not provide enough resistance to the action of gases, vapors and liquids. To the greatest extent, acrylic and organosilicon compounds are used to achieve these requirements. These compounds, modified by oxide and mineral substances of different chemical origin, due to the high permeability are mudding the pores and cracks on the surface and providing the necessary hydrophilicity and stability of the modified matrix [12]. Therefore, the aim is to study brick masonry durability for external walls of buildings using mortars based on cement which contains zeolite, and modified by air-entraining admixtures, determine properties of masonry surface treated with water repellent compounds.

\section{Materials and methods}

Portland cement (OPC) CEM I 42,5 JSC "Ivano-Frankivskcement" based on Portland cement clinker with normal mineral composition (mass.\%: $\mathrm{C}_{3} \mathrm{~S}-62.42 ; \mathrm{C}_{2} \mathrm{~S}-13.62 ; \mathrm{C}_{3} \mathrm{~A}-$ 7.06; $\mathrm{C}_{4} \mathrm{AF}-12.32$ ) was used in the investigations. Zeolite tuff were used for production of masonry cement MC 22,5X (in the amount of $\mathrm{SiO}_{2}-70-75 \%$ ) as an active mineral additive from Sokyrnytsky quarry, and limestone (with content of $\mathrm{CaCO}_{3}-95$ mass.\%) as microfiller.

The mortar prisms $(40 \times 40 \times 160 \mathrm{~mm})$ with cement-sand-water ratio of $1 / 3 / 0.5$ were prepared. The compressive and flexural strength were determined on two mortar prisms for each testing age according to EN 196-1. Physical and mechanical tests of cements and cement-sand mortars were carried out according to usual procedures. Air-entraining admixture MasterAir 81 (BASF) was used to improve the quality parameters of plasters. 
Organosilicon and acrylic compounds were used for bricks covering as hydrophobic additives.

Study of fractional composition and grinding fineness of cements were carried out by sieve analysis and determination of the specific surface area by Blaine. The chemical composition of cements and salt efflorescence was defined using X-ray spectrometer ARL 9800 XP. The phase composition of the resulting products was determined by X-ray powder diffraction: patterns were recorded at room temperature with $\mathrm{Cu} \mathrm{K} \alpha$ radiation on a PANalytical X'pert Pro diffractometer equipped with the X'celerator detector in the $2 \theta$ range from $5^{\circ}$ to $70^{\circ}$ (step $0.033^{\circ}$, time/step 50s). The powder was sieved with $63 \mu \mathrm{m}$ mesh to prepare the samples. Scanning electron microscope was used for studying the crystals of salt efflorescence on the samples and morphology of the cement stone surface.

\section{Results of investigation}

Investigation of salt efflorescence forming on the exterior walls surface of brick masonry for different building structures is made. As shown in Fig. 1a, salt efflorescence (from brick) is characterized by a high content of $\mathrm{SO}_{3}$ (51.2 mac.\%), alkaline oxides $\mathrm{Na}_{2} \mathrm{O}$ (36.7 mass.\%) and $\mathrm{K}_{2} \mathrm{O}(12.4$ mass.\%). Therewith, are fixed the negligible inclusion $\mathrm{CaO}$ (2.6 mass.\%) and $\mathrm{SiO}_{2}(1.8$ mass.\%). The chemical composition of salt efflorescence from masonry mortar (Fig. 1b) is presented by a high content of $\mathrm{CaO}(29.9$ mass.\%) and the negligible quantity of $\mathrm{SiO}_{2}\left(5.8\right.$ mass.\%). Thus the content $\mathrm{SO}_{3}$ is 7.52 mass.\%. Alkaline oxides $\left(\mathrm{Na}_{2} \mathrm{O}\right.$ and $\left.\mathrm{K}_{2} \mathrm{O}\right)$ are used in much smaller quantities.

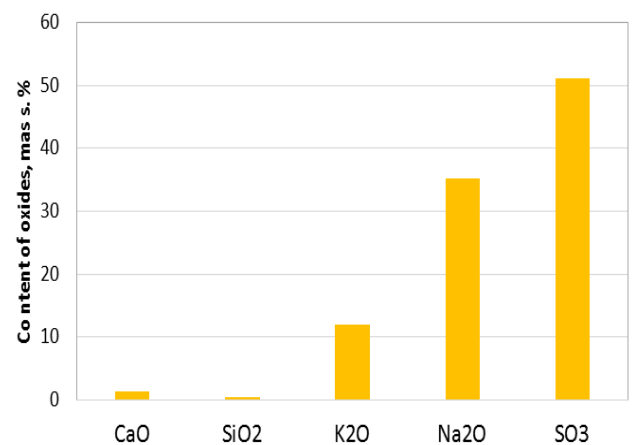

(a)

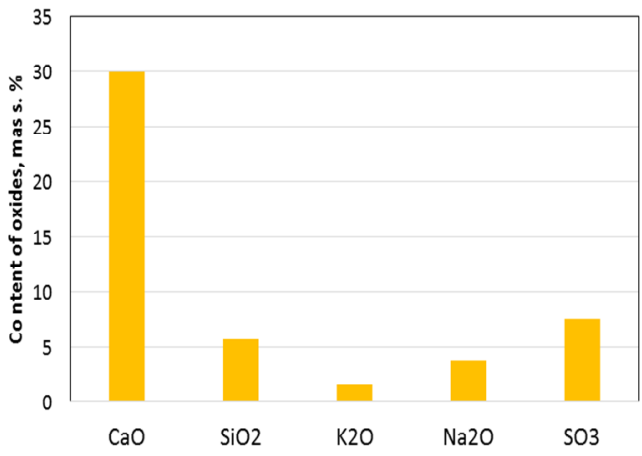

(b)

Fig. 1. The chemical composition of salt efflorescence: (a) from ceramic brick masonry; (b) from mortar masonry

According to X-ray phase analysis (Fig. 2a), crystalline phase of salt efflorescence from brick is represented mainly by lines of $\mathrm{Na}_{2} \mathrm{SO}_{4}(\mathrm{~d} / \mathrm{n}=0.467 ; 0.384 ; 0.318 ; 0.278 ; 0.264$; $0.232 \mathrm{~nm})$, arcanite $\mathrm{K}_{2} \mathrm{SO}_{4}(\mathrm{~d} / \mathrm{n}=0.288 ; 0.221 ; 0.208 \mathrm{~nm})$ and singenite $\mathrm{K}_{2} \mathrm{Ca}(\mathrm{SO})_{4} \mathrm{H}_{2} \mathrm{O}$ $(\mathrm{d} / \mathrm{n}=0.951 ; 0.285 \mathrm{~nm})$. Microstructure of salt efflorescence (Fig. 2b) is represented by different phases $\mathrm{Na}_{2} \mathrm{SO}_{4}$ and $\mathrm{K}_{2} \mathrm{SO}_{4}$. As seen in microphotography (Fig. 2c), salts $\mathrm{Na}_{2} \mathrm{SO}_{4}$ are characterized by loose, finely crystalline structure. At the same time, salts of $\mathrm{K}_{2} \mathrm{SO}_{4}$ are crystallized by aggregates similar to plates $(10-20 \mu \mathrm{m})$ in separate groups (Fig. $2 \mathrm{~d}$ ). The presence of $\mathrm{Na}_{2} \mathrm{SO}_{4}$ and $\mathrm{K}_{2} \mathrm{SO}_{4}$ phases is confirmed by EDX (Fig. 2e, g). Sodium sulphate accumulates and is bound sulphate anion to form the mineral singenite due to the increased content $\mathrm{K}_{2} \mathrm{O}$ in salt efflorescence. This can be the reason of destructive effects in the matrix of ceramic bricks and masonry. The salt crystals, filling the pores of the bricks outer layers, create the pressure and destroy the surface layers of ceramic material, which leads to the peeling of the bricks front surface and the crushing of brick masonry. 


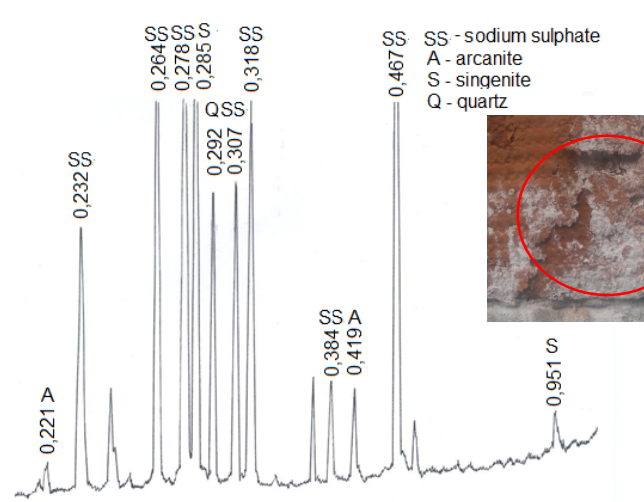

(a)

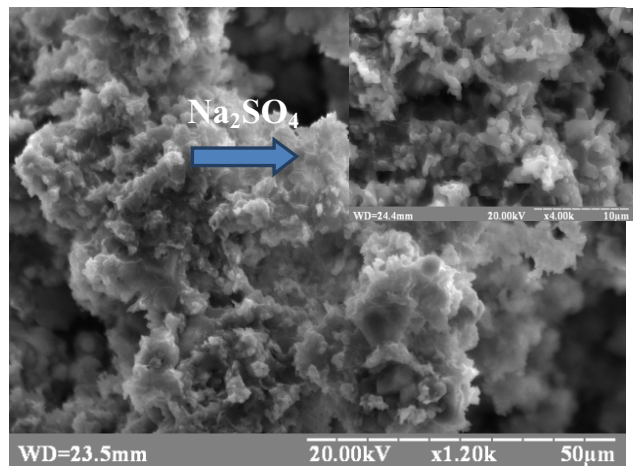

(c)

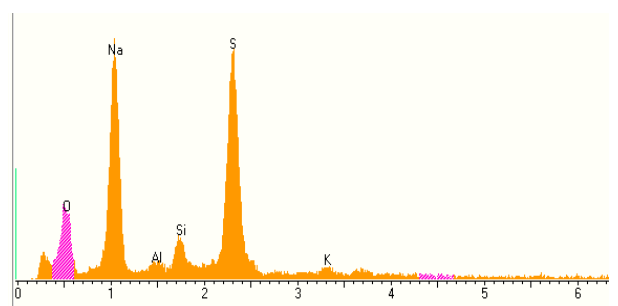

(e)

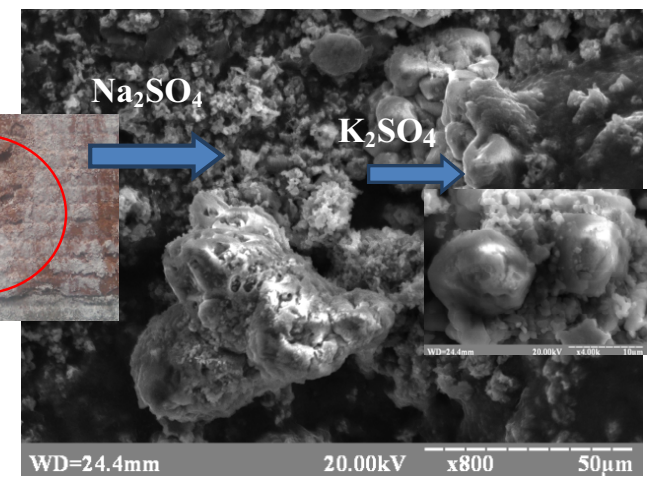

(b)

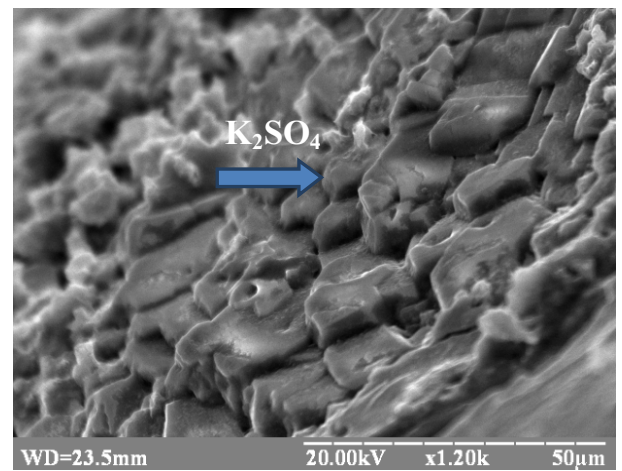

(d)

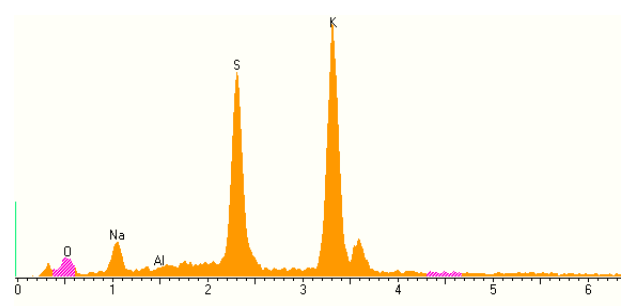

(g)

Fig. 2. X-ray powder diffraction (a), SEM images ((b, c, d) and the EDX spectrum (e, g) of salt efflorescence from ceramic bricks

The lines of calcite $\mathrm{CaCO}_{3}(\mathrm{~d} / \mathrm{n}=0.303 ; 0.249 ; 0.228 \mathrm{~nm})$, quartz $(\mathrm{d} / \mathrm{n}=0.334 \mathrm{~nm})$, $\mathrm{Na}_{2} \mathrm{SO}_{4}(\mathrm{~d} / \mathrm{n}=0.467 ; 0.384 ; 0.278 ; 0.264 ; 0.232 \mathrm{~nm})$, calcium sulphate dihydrate $\mathrm{CaSO}_{4} 2 \mathrm{H}_{2} \mathrm{O}(\mathrm{d} / \mathrm{n}=0.756 ; 0.427 \mathrm{~nm})$ characterize the salt efflorescence from mortar masonry. The negligible reflexes of singenite $(\mathrm{d} / \mathrm{n}=0.951 ; 0.285 \mathrm{~nm})$ are used. The main mineral phase of salt efflorescence from mortar masonry is calcite with addition of anhydrous sodium sulphate (tenardite) (Fig. 3b). Moreover, the layer of the mineral rashes, adjacent directly to the brick, consists mainly of calcite which increases the tenardite (Fig. $3 \mathrm{c})$. It should be noted the prevailing growth of ions concentration of $\mathrm{Ca}^{2+}$ and $\mathrm{SO}_{4}{ }^{2-}$ due to the formation of gypsum dihydrate $\mathrm{CaSO}_{4} 2 \mathrm{H}_{2} \mathrm{O}$. 


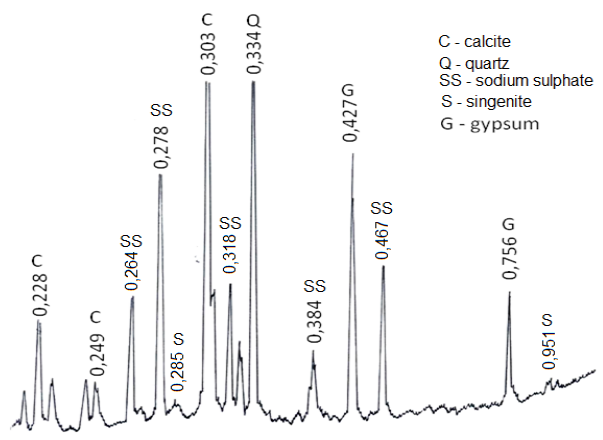

(a)

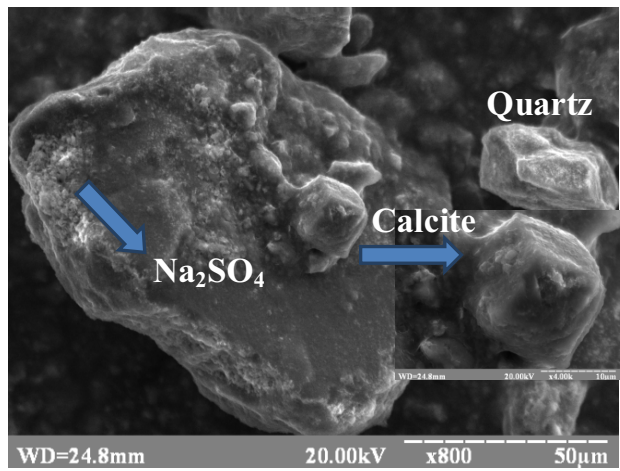

(c)

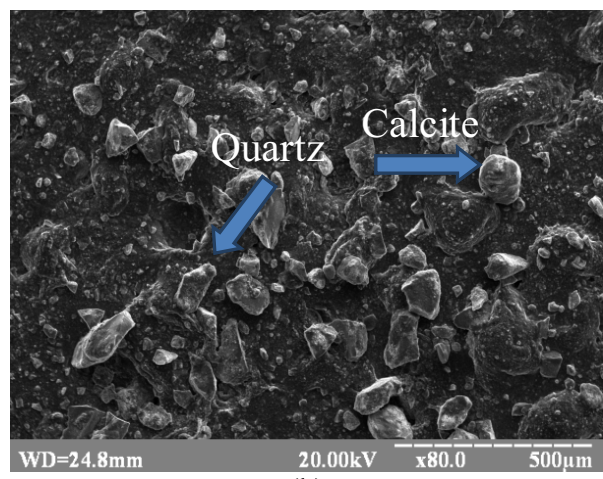

(b)

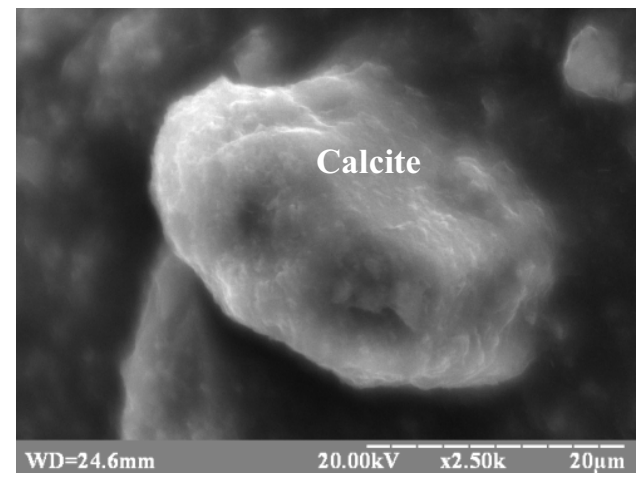

(d)

Fig. 3. X-ray powder diffraction (a) and SEM images (b, c, d) of salt efflorescence from mortar masonry

The special masonry cement complied with class MC 22,5 X DSTU B EN 413-1:2015 with low-clinker content (40 mass.\%) is used to prevent the formation of salt efflorescence on the masonry surface of exterior walls in the mortar. Water demand of multi-component cement $\left(\mathrm{SSA}=7600 \mathrm{~cm}^{2} / \mathrm{g}\right)$ is $31.8 \%$, initial setting time $-160 \mathrm{~min}$, final $-210 \mathrm{~min}$, volume coefficient of water separation is $4.8 \%$. Standard cone flow for multi-component cement is $162 \mathrm{~mm}$ (Fig. 4a). Compressive strength after 2, 7 and 28 days of hardening is 7.6, 16.1 and 34.7 MPa, respectively, according to EN 196-1 (Fig. 4b).

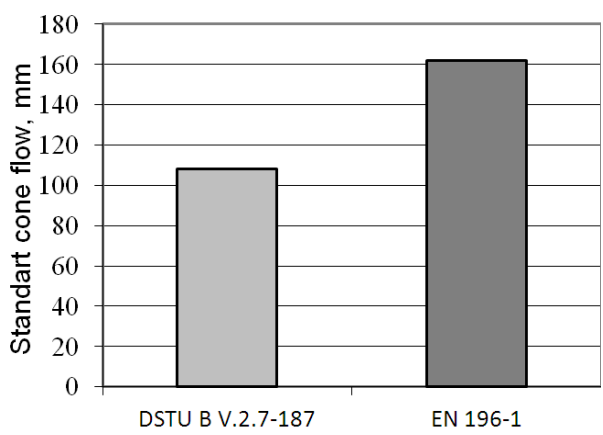

(a)

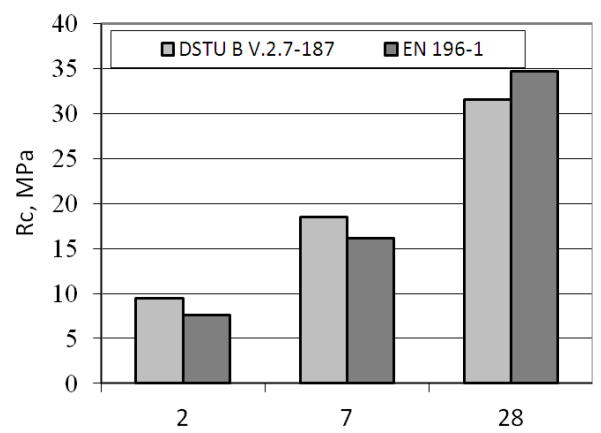

(b)

Fig. 4. Standart cone flow (a) and compressive strength (b) of cement $\mathrm{MC} 22,5 \mathrm{X}$ according to DSTU B. V.2.7-187 and EN 196-1 
The lines of calcite $(\mathrm{d} / \mathrm{n}=0.303 ; 0.249 \mathrm{~nm})$ and crystalline hydrate phases: calcium hydroxide $(\mathrm{d} / \mathrm{n}=0.490 ; 0.263 ; 0.192 \mathrm{~nm})$, ettringite $(\mathrm{d} / \mathrm{n}=0.973 ; 0.388 \mathrm{~nm})$ and a certain amount of calcium hydroaluminate $\mathrm{C}_{4} \mathrm{AH}_{13}(\mathrm{~d} / \mathrm{n}=0.81 \mathrm{~nm})$ are observed on diffractograms of cement stone based on $\mathrm{MC} 22,5 \mathrm{X}(\mathrm{W} / \mathrm{C}=0.34)$ after 28 days of hydratation by the $\mathrm{X}$-ray analysis method (Fig. 5). It is observed a decrease of calcite lines $\mathrm{CaCO}_{3}$ and presence of intensive lines of hydrocarboaluminate $\mathrm{C}_{3} \mathrm{~A} \cdot \mathrm{CaCO}_{3} \cdot \mathrm{H}_{2} \mathrm{O}(\mathrm{d} / \mathrm{n}=0.76 ; 0.380 \mathrm{~nm})$, which indicate partial transformation of hexagonal hydroaluminate into hydrocarboaluminate after 28 days of hydration.

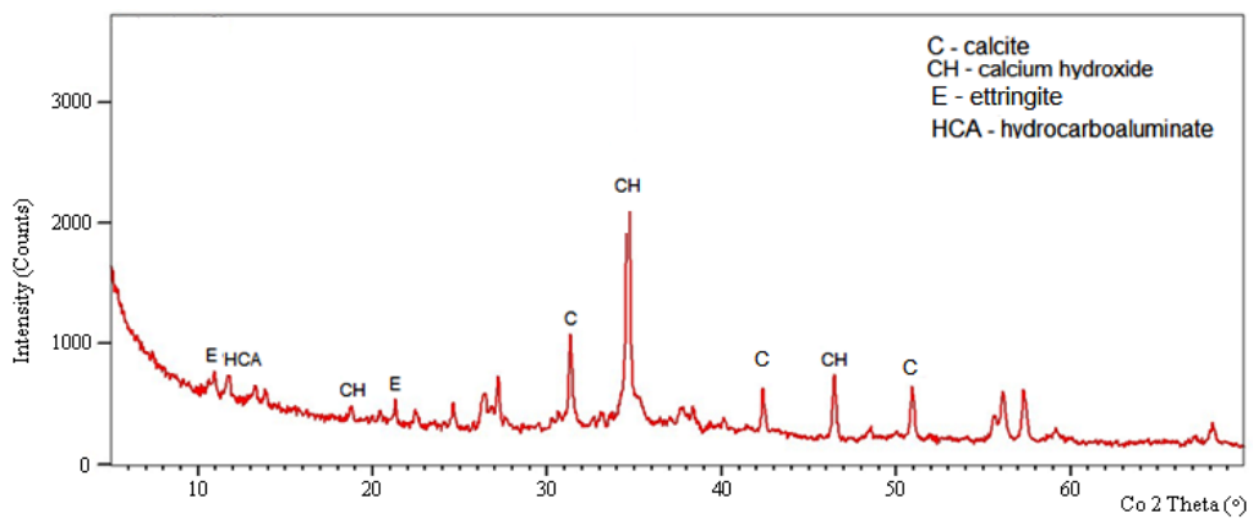

Fig. 5. X-ray powder diffraction of cement MC $22,5 \mathrm{X}$ after 28 days of hardening

The addition of highly active mineral additives to cement MC 22,5 $\mathrm{X}$ allow reducing the calcium hydroxide in 2.2 times compared with a stone based on CEM I after 28 days of hydration. The dense structure of the hydrated solid phase is provided by $\mathrm{AF}_{\mathrm{m}}{ }^{-} \mathrm{i}_{\mathrm{AF}_{\mathrm{t}}}{ }^{-}$ phases in gel-like C-S-H phase. Active forms of $\mathrm{SiO}_{2}$ and $\mathrm{Al}_{2} \mathrm{O}_{3}$ in the composition of aluminum-containing pozzolana promote better binding of calcium hydroxide into lowbasic calcium hydrosilicates, which indicates the acceleration of puzzolanic reaction. Fine limestone stabilizes hydration products of tricalcium aluminate with formation of hexagonal hydrocarboaluminate $\mathrm{C}_{4} \mathrm{~A} \cdot \mathrm{CO}_{2} \cdot 12 \mathrm{H}_{2} \mathrm{O}$ during hydration of the clinker component.

The quantity of air-entraining admixtures largely determines the porosity of mortar. For mortar with the addition of lime the total porosity is $23.17 \%$ (open $-16.68 \%$, closed $6.49 \%)$. At the same time, the total porosity for modified mortar $\left(\rho=1860 \mathrm{~kg} / \mathrm{m}^{3}\right)$ increases to $26.77 \%$, but the ratio between the open and closed porosity changes $(7.61$ and $19.16 \%$ respectively). The addition of $0.03 \ldots . .0 .05 \%$ of air-entraining admixtures by mass leads to the reduction of the average pores size to $2.77 \ldots 1.95$. The application of multi-component cement, which contains zeolite, provides for formation of a denser mortar matrix which reduces the motion of pore hydrates and thus reduces efflorescence formation.

The method of scanning electronic microscopy proves that structure of cement stone is condensed by colmatation of open pores of Portlandite and $\mathrm{AF}_{\mathrm{m}}$-phases (Fig. 6a). Hydrophobic plastifying admixtures cause the formation of numerous elastic air bubbles which spread on the whole cement paste uniformly. Fig. 6b displays the closed air pore of 5 $\mathrm{mm}$ in diameter. In the freshly-mixed mortar, spherical bubbles reduce the inner friction, plasticize and prevent its components from segregation. Due to the aeration, the building mortar is characterized by lower absorption ability, it is more resistant to atmospheric influences and more resistant to the multiple cycles of freezing and thawing, as water that freezes in the capillaries has the ability to penetrate into empty bubbles which prevent the cracking, and thus play the role of "buffers" - stress dampers [10]. 


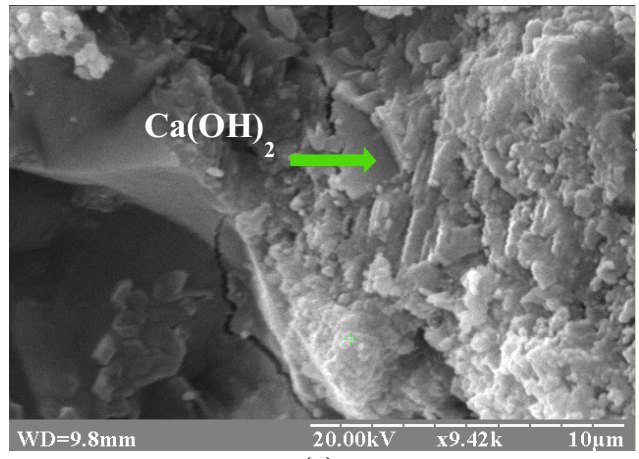

(a)

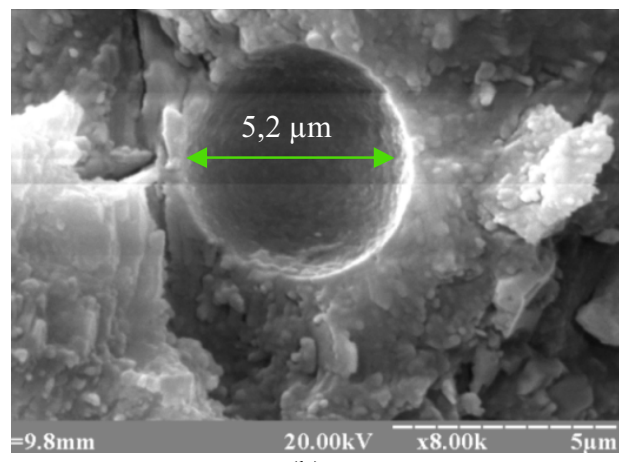

(b)

Fig. 6. The microstructure of the cement stone after the 28-day hydration with the addition of compound air entraining agent: (a) open pore, (b) closed air pore

According to the thermogravimetry data, in modified mortars comprising after 3 months of hardening in the air-dry conditions $\mathrm{LOI}=7.38$ mass. $\%$, the content of bound water equals to 3.10 mass. $\%$, or in relation to cement -14.39 mass. $\%$, the content of $\mathrm{Ca}(\mathrm{OH})_{2}$ and $\mathrm{CaCO}_{3}-2.80$ and 7.27 mass.\% accordingly. This shows that over $50 \%$ of water evaporates during the hardening. For the mortar with the addition of 20 mass.\% of lime paste $\mathrm{LOI}=9.16 \%$ (including the amount of bound water $-2.50 \%$ ), and the content of $\mathrm{Ca}(\mathrm{OH})_{2}$ and $\mathrm{CaCO}_{3}$ equals to 2.61 and 12.15 mass.\% accordingly, thus in a mortar containing lime paste the loss of water is more intense and through the open capillary pores is also accompanied by substantial carbonization.

The necessary complex of the quality parameters of high-performance mortar had been analyzed and the results showed that the workability of modified mortar mixtures was characterized by the ability to water-retention $96-97 \%$ and by segregattion $-7-8 \%$. Modified mortars $\left(f_{c}=10.4 \mathrm{MPa}\right)$, possess minor shrinkage deformations $(0.31 \mathrm{~mm} / \mathrm{m}), 75$ cycles of freezing and thawing and are characterized by reduced efflorescence.

The mortar is characterized by smaller water absorption and higher resistance against the atmospheric influences and repeated cycles of freezing due to aeration, because the water that freezes in the capillaries can compress into empty bubbles that prevent cracking, acting as "shock absorbers" - the stresses dampers. Modified masonry mortars based on MC 22,5X provide the high quality of masonry (completeness and uniformity of the seam filling, observance of their rational thickness), an adhesion of the mortar and also strength, deformation and stability to salt efflorescence on the surface of the walls. The compressive strength of masonry is $3.5 \mathrm{MPa}$, when modified mortar and ceramic bricks are used. So the compression strength of masonry due to the emergence of a complex stress state is 2.8 times less compared with the strength of brick and mortar.

One of the effective ways to protect the ceramic brick from the destructive action of moisture and salts is its processing impregnation by ecologically safe chemicals compound of multifunctional action. It was done the physical and chemical surface modification of ceramic bricks (depth impregnation - 2.1 - $3.1 \mathrm{~mm}$ ) by organosilicon and acrylic compounds. Experimental investigations have established that ordinary ceramic bricks (compression strength $-10 \mathrm{MPa}$, average density $-1647 \mathrm{~kg} / \mathrm{m}^{3}$, porosity $-24.3 \%$ ) and modified ceramic bricks with protective coating according to water absorption index reduced $8.2-8.4$ times and water resistance and frost resistance increased, respectively, by $6.2-17.5 \%$ and $55-64 \%$. The use of organosilicon compounds provides a compaction of the structure of ceramic brick surface, the high resistance to water permeability and salt solutions and durability. 


\section{Conclusions}

The local white spots of salt efflorescence lead to destructive phenomena in the brick masonry. The use of multimodal cements provides compacting mortar matrix structure, reduces shrinkage and water absorption, increases water resistance and fracture toughness of mortars and allows obtaining plastered surfaces without efflorescence. Synergistic combination of mineral additives of different groups with substantial reduction of highenergy-consumption clinker component content in multi-component cement MC 22,5X allows improving the technological characteristics of mortar mixes and quality of brick masonry. Physical and chemical modification of mortars with highly effective complex aeration additives becomes one of the main solutions to the problem of salt efflorescence and masonry durability for exterior walls of buildings and structures.

This research was supported by Prof., Dr.Sc., Myroslav Sanytsky

\section{References}

1. H. Brocken, T. G. Nijland. Constr. and Build. Materials, 18, 315-323 (2004)

2. C. Dow, F.P Glasser. Cem. Concr. Res., 33, 147-154 (2003)

3. N. Sghaier, M. Prat. Transport in Porous Media, 80, 441 - 454 (2009)

4. A. Mobili, A. Belli, C. Giosuè, T. Bellezze, F. Tittarelli. Cem. Concr. Res., 88, 198210 (2016)

5. M. Muller, H-M. Ludvig, M. Ben Haha, M. Zajac. 19th Internationale Baustofftagung, 1, 449-456 (2015)

6. M. Sanytsky, T. Kruts, T. Kropyvnytska, B. Rusyn. 14th International Congress on the Chemistry of Cement, 1, 265 (Beijing, China, 2015)

7. C. Bilim. Constr. and Build. Materials, 25, 3175-3180 (2011)

8. J. Shibata, N. Murayama, T. Masui, S. Yao, T. Toyofuku, 41, 67-71 (2015)

9. B. Klimek, D. Barnat-Hunek, M. Franus. Proceedings of Lviv Polytechnic National University, 781, 72-78 (2014)

10. M. Sanytsky, T. Kropyvnytska, R. Kotiv. Advanced Materials Research, 923, 42-47 (Switzerland, 2014)

11. A. Izaguirrea, J. Lanasb, J. Álvareza. Cem. Concr. Res., 39, 1095-1104 (2009)

12. H. Zhu, P. Wang, R. Wang, G. Zhang. Materials science, 20, 345-350 (2014) 